K

Сомбинированная терапия акне у женщин: поиск оптимальных решений

\author{
М.В. Горячкина, Т.А. Белоусова
}

ГБОУ ВПО «Первый Московский государственный медицинский университет им. И.М. Сеченова» Минздрава России

119991, Москва, ул. Трубецкая, д. 8, стр. 2

Представлены современные данные о патогенезе акне. Акцентируется внимание на увеличении встречаемости дерматоза в зрелом возрасте у женщин. Подробно освещены вопросы клиники, влияния экзогенных и эндогенных факторов на течение акне, психосоциальные аспекты поздних проявлений акне у женщин. Обсуждается важная роль лечебно-косметических средств в комплексной терапии акне. Приводится собственный опыт лечения нетяжелых фрорм поздних акне с использованием лечебно-косметических средств гаммы Исеак в сочетании с микродермабразией, безыгольной мезотерапией на аппарате Vita Peel/Vital O.

Ключевые слова: акне, эпидемиология, патогенез, клинические особенности, методы лечебнокосметологической коррекции поздних акне у женщин, лечебно-косметические препараты линии Исеак, микродермабразия, безыгольная мезотерапия, аппарат Vita Peel/Vital $\mathbf{0}_{2}$ :

Контактная информация: belka-1147@mail.ru. Вестник дерматологии и венерологии 2014; (2): 90—95.

\title{
Combination therapy of acne in women: searching for optimum solutions
}

\author{
M.V. Goryachkina, T.A. Belousova
}

I.M. Sechenov First Moscow State Medical University

Trubetskaya str., 8, bldg 2, Moscow, 119991, Russia

\begin{abstract}
Current data on the acne pathogenesis are given. According to the authors, dermatosis is becoming more prevalent among women of mature age. Issues related to the clinical picture, effect of exogenous and endogenous factors on the course of acne, and psychosocial characteristics of delayed acne manifestations in women are described in detail. The essential role of medical and cosmetic products for the complex therapy of acne is discussed. The authors describe their own experience of treating delayed acne using the Hyseac line of medical and cosmetic products in a combination with microdermabrasion and no-needle mesotherapy using the VitaPeel/Vital $\mathrm{O}_{2}$ device.
\end{abstract}

Key words: acne, epidemiology, pathogenesis, clinical characteristics, methods of medical and cosmetic correction of delayed acne in women, medical and cosmetic products from the Hyseac line, microdermabrasion, no-needle mesotherapy, VitaPeel/Vital $\mathbf{0}_{2}$ device. 
Акне - широко распространенное хроническое заболевание кожи со сложным мультифакторным патогенезом, требующее длительной комбинированной терапии. В возрасте 13-25 лет проявления дерматоза отмечаются у 65-95\% людей. В последнее время все чаще встречаются пациенты с проявлением заболевания в зрелом возрасте. По данным отечественных исследований, у 38\% угревые высыпания выявлялись в возрасте 25-35 лет, а у 12,5\% - в возрасте 35-45 лет [1].

Современные исследования показали, что ведущим механизмом развития акне является воспаление, а также повышенная продукция измененного по составу кожного сала, нарушение процессов кератинизации в области сально-волосяного аппарата, избыточная способность кератиноцитов к сцеплению и гиперколонизация патогенными микроорганизмами, главным из которых является $P$. acnes. Выявлено, что провоспалительная активность $P$. acnes выше, чем у Staphylococcus aureus и Streptococcus. Поздние акне у женщин протекают на фроне гиперандрогении (ГА), которая является инициальным звеном заболевания. ГА может проявляться в виде абсолютного увеличения количества андрогенов овариального или надпочечникового происхождения в крови и при экскреции с мочой (встречается у женщин репродуктивного возраста) или в виде повышенной чувствительности рецепторов (рецепторная ГА) к нормальному или сниженному количеству андрогенов. Основной причиной рецепторной ГА является повышение активности фрермента $5 \alpha$-редуктазы I, которая переводит тестостерон в более активный метаболит дегидротестостерон (ДГТ), являющийся непосредственным стимулятором пролиферации и созревания себоцитов. Таким образом, ГА оказывает стимулирующее действие на сальные железы, увеличивая объем кожного сала. Выявлено, что продукция кожного сала при легкой степени акне увеличивается в 1,3 раза, при средней - в 1,7 раза, а при тяжелой - в 1,9 раза [2-6].

В настоящие время ключевую роль отводят воспалительной реакции, которая предшествует фолликулярной гиперкератинизации. Ведущую роль в регуляции фолликулярной гиперкератинизации играет интерлейкин-1 $\alpha$ посредством влияния на концентрацию $\alpha$-линоленовой кислоты и активность пролиферации фолликулярных кератиноцитов, которая у больных с акне в фролликулах на видимо здоровой коже выше, чем у здоровых людей [6].

Результаты различных зарубежных клинических исследований свидетельствуют, что $P$. acnes могут активировать экспрессию Тоll-подобных рецепторов (TLR2 и TLR4), приводя к развитию воспаления при акне. Кроме того, выявлено, что при акне активизируются антимикробные пептиды: бета-дефензины и кателецидин, и установлено, что $P$. acnes могут активировать систему инсулиноподобного фрактора роста-1 и его рецептора (IGF-1/IGF-R1) в эпидермисе, действуя как инсулин и способствуя пролиферации кератиноцитов. Однако, согласно последним исследованиям, не все штаммы $P$. acnes патогенны. По данным S. FitzGibbon, S. Tomida, B. Chiu и соавт., из выделенных 66 штаммов $P$. acnes у больных с угревыми высыпаниями преобладают 2 штамма бактерий: RT4 и RT5, a в коже здоровых людей - RT6. Этот «хороший» штамм имеет гены, позволяющие бороться с бактериями, вирусами и другими инфекционными агентами. По всей видимости, он также способен подавлять рост штаммов RT4 и RT5, предотвращая развитие воспаления в сальной железе [7-10].

В последние годы пересмотрен подход к акне исключительно как к подростковому заболеванию, так как растет число пациентов, у которых угревые высыпания встречаются в возрасте 25 лет и старше. Причем Ch. Colleir и соавт. подчеркивают, что если в подростковом возрасте заболеваемость акне практически одинакова среди представителей обоих полов, то при поздних угрях (acne tarda) существенно преобладают женщины. В ряде европейских исследований было отмечено, что у девушек 20-29 лет акне встречаются в $51 \%$ случаев, а у женщин в возрасте 25-40 лет угревые высыпания выявляются в 41$54 \%$ случаев. По данным отечественных исследований, в последнее время наметилась тенденция к увеличению числа женщин, у которых дебют заболевания приходится на возраст 18 лет и старше. В США с 1990 по 1999 г. средний возраст больных с акне увеличился с 26,5 до 40,5 года. По данным ряда авторов, средний возраст пациенток с акне составляет 31,8 [11] и 32,4 [13] года.

Поздние фрормы акне у женщин помимо позднего дебюта заболевания характеризуются длительным персистирующим течением, чередованием периодов обострений и ремиссий, резистентностью к проводимой терапии. Локализация высыпаний на лице вызывает у пациенток постоянный психологический дискомфорт, негативно влияет на их социальный и профессиональный статус и значительно снижает качество жизни $[1,2,6,11,16,17]$.

В большинстве случаев пациентки с acne tarda имеют легкую и среднетяжелую фрормы заболевания. В основном преобладают папулезные и папуло-пустулезные высыпания, реже комедональные элементы; узловатые формы угрей встречаются крайне редко. Высыпания, как правило, локализуются в области нижней трети лица, подбородка, шеи и периоральной области. Высыпания в области лба и щек встречаются реже. Верхняя треть груди и спины, а также плечи практически не вовлекаются в патологический процесс. У $20 \%$ женщин отмечаются регулярные предменструальные обострения в виде появления 1-3 свежих акне за 2-5 дней до начала очередной менструации с последующим полным регрессом высыпаний после 
окончания menses. Для девушек с поздними угрями характерно и частое проявление симптомокомплекса «постакне» в виде гиперпигментации и рубцов $[11,17]$.

В клинической практике различают две клинические формы поздних акне у женщин $[16,18]$.

1. Воспалительная фрорма характеризуется появлением папуло-пустулезных элементов и в более редких случаях - узлов, приводящих к рубцам. Себорейные явления выражены незначительно. По данным ряда авторов, эта форма заболевания встречается у 58\% женщин.

2. Невоспалительная форма характеризуется гиперсебореей, закрытыми и открытыми комедонами, а также наличием небольшого количества воспалительных элементов. Высыпания в большинстве случаев локализуются на лице, в особенности в области лба.

Наиболее часто у пациенток наблюдаются персистирующие акне, тянущиеся с подросткового периода (около 80\% женщин), реже встречаются акне позднего дебюта, возникающие в среднем в возрасте 25 лет (около 20\% [11]); рецидивирующие акне, так называемые акне со светлым промежутком, выявляются в клинической практике наиболее редко $[11,16]$.

К ухудшению течения акне приводят [6, 11, 16-19]:

п постоянная механическая травматизация кожи (выдавливание угрей, нерациональный уход за кожей, частое мытье с мылом);

негативное воздействие внешней среды (загрязнение кожи маслами, бензином, пылью производственного происхождения);

прием ряда лекарственных препаратов (глюкокортикостероиды, галогенсодержащие препараты, противотуберкулезные средства, антидепрессанты, противоэпилептические средства);

использование косметических средств, дающих комедогенный эфффект;

курение (никотин провоцирует продукцию кожного сала и снижает концентрацию витамина Е);

- пищевые продукты со значительным содержанием сахара и других углеводов (увеличивают уровень гликемической нагрузки, таким образом оказывая влияние на концентрацию инсулина и инсулиноподобного фрактора роста-1, способных повысить концентрацию основных андрогенов в плазме крови);

стресс (выработка нейромедиаторов, таких как субстанция $\mathrm{P}$, которая влияет на диффференцировку и деление себоцитов, стимулируя продукцию кожного сала);

УФ-излучение (у 8-10\% пациентов).

При акне велика роль психоэмоциональных нарушений, связанных с проблемой «дефекта внешности». Локализация дерматоза на открытых участках кожи: лице, верхней половине груди и спине приносит пациентам, особенно девушкам и женщинам, глубокие психические страдания, негативно влияя на качество жизни, социальный статус, профессиональную деятельность и личную жизнь, самооценку, вызывая тревогу, депрессию, способствуя развитию дисморфофобии [20-22].

Это, в свою очередь, приводит к различной степени выраженности социальной дезадаптации и значительному снижению качества жизни. Установлено, что среди лиц с акне отмечается большое количество (64\%) неработающих женщин, a S. Kellet в своих исследованиях подчеркнул, что женщины с акне являются наиболее психологически уязвимыми по сравнению с мужчинами. По данным J. Tan и соавт., женский пол, зрелый возраст, длительность (более 5 лет) заболевания являются дополнительными фракторами, оказывающими негативное влияние на качество жизни женщин, существенно снижая его [22-24].

Согласно исследованиям И.В. Кондратенко, длительное персистирующее течение акне и нерационально подобранная терапия заболевания у молодых женщин вызывают выраженные психоэмоциональные нарушения, способствующие обострению сопутствующих заболеваний. В других отечественных исследованиях было выявлено, что у женщин отмечается более высокий уровень тревожности по сравнению с мужчинами и они более склонны к развитию депрессивной симптоматики в отличие от пациентовмужчин [1, 21, 25].

Современные подходы к лечению акне у женщин включают прежде всего назначение топической противоугревой терапии, которая является базисной, так как у женщин с поздними угрями преобладают в основном нетяжелые формы заболевания. При неэффрективности местной терапии назначается системная терапия. В случае выявления патологии в гормональном статусе системная терапия назначается по согласованию с эндокринологом-гинекологом (см. таблицу). На любом этапе заболевания существенно расширяют и дополняют базисную терапию средства лечебной косметики и аппаратные дерматокосметологические методы терапии [26].

Одним их эффективных методов терапии акне, а также постакне является проведение процедур микродермабразии в сочетании с безыгольной мезотерапией на аппарате Vita Peel/Vital $\mathrm{O}_{2}$ в комплексе с лечебными косметологическими средствами (ЛКС), направленными на коррекцию различных проявлений акне. Процедура выполняется в два этапа. Первый этап состоит из двух частей. Сначала в течение 5-7 мин. проводится вакуумная стимуляция по массажным линиям, направленная прежде всего на улучшение насыщения клеток кислородом, стимуляцию регенерации клеток. Далее в течение 20-25 мин. проводится микродермабразия (испускание тонкого пучка микрокристаллов оксида алюминия на поверхность кожи). Микродермабразия позволяет удалить 


\begin{tabular}{|c|c|c|}
\hline Топическая терапия & Системная терапия & $\begin{array}{c}\text { Другие дерматокосметологические методы } \\
\text { лечения }\end{array}$ \\
\hline Азелаиновая кислота & Антибиотики & $\begin{array}{c}\text { Пилинги (механические, химические, сризические) } \\
\text { Неодимовый лазер }\end{array}$ \\
\hline Ретиноиды & $\begin{array}{c}\text { Комбинированные оральные контрацептивы } \\
\text { с антиандрогенным действием }\end{array}$ & $\begin{array}{c}\text { Дермабразия ( } \mathrm{CO}_{2}, \text { эрбиевый лазер) } \\
\text { Дарсонвализация }\end{array}$ \\
\hline Бензоилпероксид (БПО) & Системные ретиноиды & $\begin{array}{c}\text { Криомассаж } \\
\text { Фототерапия (PhotoDyn 750): }\end{array}$ \\
\hline Антибиотики & & $\begin{array}{c}\text { синий свет } \\
\text { с фоотосенсибилизатором (аминолевулиновая кислота, }\end{array}$ \\
\hline Комбинированные средства: & & $\begin{array}{c}\text { метвикс) } \\
\text { Ультразвуковая терапия }\end{array}$ \\
\hline ретиноид + БПО & & Микротоковая терапия \\
\hline ретиноид + антибиотик & & Аппаратные методы с использованием косметических \\
\hline $\begin{array}{l}\text { антибиотик + БПО } \\
\text { антибиотик + Zn }\end{array}$ & & $\begin{array}{c}\text { средств по проблеме } \\
\left(\text { Vita Peel/Vital } 0_{2}\right)\end{array}$ \\
\hline
\end{tabular}

омертвевшие клетки кожи, сгладить десректы, подготовить кожу к проникновению лекарственных средств. На втором этапе на кожу наносятся ЛКС в зависимости от выраженности салоотделения, а также наличия комедонов, папул, пустул, гиперпигментных пятен. Струя кислорода переносит активные ингредиенты препаратов через межклеточное пространство эпидермиса к базальному слою, в результате чего в зоне введения формируется депо активных компонентов. Так как базальный слой находится в непосредственном контакте с дермой, данный режим обеспечивает наиболее полный и пролонгированный эффект ЛКС. Таким образом, сочетание двух приборов Vital $\mathrm{O}_{2}$ (система кислородной терапии) и VitaPeel/VitaPeel Ion (системы микродермабразии) позволяет проводить кислородную микродермабразию. Кислород в потоке кристаллов обеспечивает щадящий пилинг, дает выраженный антибактериальный, регенерирующий и метаболический эфрфекты. Режим вакуумной стимуляции не рекомендован при гиперпигментации, в этом случае следует прибегать к микродермабразии. Процедуру нужно начинать с очищения, желательно из гаммы лечебных средств, которые будут использоваться по проблеме. К основным противопоказаниям процедуры относятся: наличие герпетической инфекции, розацеа, тяжелые формы акне, диабет, гемофилия, онкологические заболевания, новообразования в области лица, ВИЧ-инфекция, прием лекарственных средств, влияющих на фроточувствительность.

Под нашим наблюдением находились 15 пациенток в возрасте от 25 до 33 лет (средний возраст 27,4 года) с комедональной и папуло-пустулезной формами. Давность заболевания варьировала от 1 года до 14 лет и в среднем составила 6,5 года. У большинства пациенток - у 9 (60\%) наблюдались персистирующие акне. У 6 (40\%) женщин отмечались акне позднего дебю- та, впервые возникшие в возрасте 25-26 лет. У всех пациенток высыпания локализовались в области лица: периоральная область, подбородок, лоб, реже щеки. У 6 (40\%) женщин отмечались явления постакне в виде гиперпигментированных очагов. 5 (33,3\%) женщин имели проблемы гормонального характера (повышение уровня основных андрогенов, патология по ультразвуковой картине органов малого таза) и получали соответствующую терапию у гинеколога-эндокринолога.

В коррекции угревых высыпаний мы использовали ЛКС компании «Урьяж» в сочетании с аппаратными методами на аппарате Vita Peel/Vital $\mathrm{O}_{2}$. ЛКС линии Исеак компании «Урьяж» прекрасно зарекомендовали себя в комплексной терапии acne tarda благодаря уникальному составу, легкой текстуре, удобству применения, возможности сочетания с противоугревыми препаратами и фризиокосметологическими методами лечения, а также наличию в линии нескольких средств, потенцирующих и дополняющих действие друг друга. Процедуры проводили раз в 10 дней. Всего на курс 4-5 процедур.

Перед каждой процедурой кожу пациенток предварительно очищали мицеллярным раствором (очищающая вода) Урьяж для нормальной и комбинированной кожи. Данное средство предназначено для людей с чувствительной кожей, и его также можно использовать для демакияжа контура глаз. Очищающая вода содержит в своем составе мягкие сурфактанты и экстракт граната. Экстракт граната является уникальным компонентом косметологических средств, в своем составе он содержит танин, поэтому его добавляют в рецептуры средств для жирной кожи. Активные вещества граната также питают, увлажняют кожу, способствуют активной регенерации, препятствуют потере эластичности кожи. Кроме того, 
экстракт граната имеет легкий отбеливающий и отшелушивающий эффрект, что немаловажно у пациентов с акне и пигментацией.

Далее пациенткам с комедональными акне и без наличия гиперпигментированных очагов в течение 5 мин. проводили вакуумную стимуляцию по массажным линиям, готовя кожу к процедуре микродермабразии. Микродермабразию проводили в течение 25 мин., далее наносили крем Исеак К18. Это новое инновационное средство гаммы, воздействующее на комедональные акне. Входящие с его состав компоненты помимо щадящего кератолитического эффекта оказывают себоредуцирующее и противовоспалительное действие, что приводит к активному регрессу комедонов и устраняет жирный блеск. И наконец, третьим этапом проводили безыгольную мезотерапию под давлением кислорода (90-95\%) в течение 20 мин.

У пациенток с папуло-пустулезными акне пропускали этапы вакуумной стимуляции и микродермабразии, а после очищения кожи сразу наносили крем Исеак A.І. Данный препарат содержит уникальный компонент - TLR2-регулирующий комплекс, который оказывает противоспалительное действие, связанное с активацией TLR2-рецепторов, уменьшает выброс медиаторов воспаления, таких как IL-8, таким образом регулируя воспалительный процесс на ранней стадии. В состав крема входит ВНА, усиливающие противоспалительный эфффект, а антимикробное действие достигается за счет наличия пироктоноламина. После нанесения Исеак А.І проводили кислородную мезотерапию.

Шести женщинам с поствоспалительной гиперпигментацией на очаги наносили Депидерм - эмульсию против пигментных пятен. Эмульсия содержит никотинамид, позволяющий уменьшить выраженность пигментации. Подобный эффект связан с нарушением переноса меланосом из меланоцитов в кератиноциты. Входящая в препарат солодка обладает выраженным отбеливающим свойством, а векторизированный витамин С оказывает мощное гипопигментирующее действие при нанесении на гиперпигментированные очаги.

Для коррекции нежелательных явлений, таких как сухость, шелушение, раздражение кожи, возникающих в процессе лечения, использовали специальный восстанавливающий крем гаммы Исеак (специаль- но предназначенный для жирной и комбинированной кожи), в состав которого включен запатентованный комплекс Церастерол-2F®, который восстанавливает нарушенный кожный барьер, успокаивает, увлажняет кожу, укрепляет ее защитные функции. При необходимости в лечебный комплекс включали Цикактив P.I, способствующий эффективному восстановлению эпидермиса после проведения дерматоэстетических процедур.

После проведения лечебной процедуры на аппарате Vita Peel/Vital $\mathrm{O}_{2}$ и в промежутке между ними с целью профилактики возникновения фоточувствительных реакций всем женщинам было рекомендовано использование фотозащитных средств линии Исеак. Солнцезащитные эмульсии этой линии предназначены именно для пациенток с жирной или комбинированной кожей, склонной к образованию невоспалительных и воспалительных акне.

На фоне лечения в обеих группах отмечалась положительная динамика кожного процесса. Прекращалось появление новых комедональных и папуло-пустулезных элементов, наблюдалось значительное уменьшение сальности и пористости кожи, она становилась более гладкой, матовой, разглаживались мелкие морщинки, уменьшалась выраженность гиперпигментации кожи. Кожа приобретала свой естественный цвет, выравнивался ее рельеф. Большинству пациенток было достаточно 4 процедур. Только 2 женщинам понадобилась дополнительная пятая процедура.

Переносимость комплексной терапии была хорошая. При применении гаммы Исеак в сочетании с микродермабразией и безыгольной кослородной мезотерапией случаев отмены или отказа от лечения не выявлено. Аллергических и побочных реакций не отмечалось.

Таким образом, ЛКС линии Исеак в сочетании с аппаратными методами Vita Peel/Vital $\mathrm{O}_{2}$ являются эффрективным и безопасным методом косметологической коррекции угревых высыпаний у женщин c acne tarda. Комбинированная терапия, воздействуя на основные проявления акне, обладая выраженным себастатическим, кератолитическим противоспалительным и противомикробным свойствами, активно способствует регрессу элементов, проявлений постакне и существенно расширяет возможности терапии у женщин с поздними акне. 


\section{Литература}

1. Yutskovskaya Ya.A., Taran M.G., Dvoryaninova I.E. Principles of topical acne treatment in combination with apparatus exposures. 2012; 3 : 1-4. ГЮцковская Я.А., Таран М.Г., Дворянинова И.Е. Принципы наружного лечения акне в сочетании с аппаратными методами воздействия. Экспер и клин дерматокосметол 2012; (3): 1-4.]

2. Dobrochotova Ya.E., Dzobava E.M., Ragimova Z.Ya. et al. Syndrome of hyperandrogenism in practice obstetrician-gynecologist, dermatologist, endocrinologist. Guide for Physicians M:GEOTARpMedia 2009. [Доброхотова Ю.Э., Джобава Э.М., Рагимова 3.Ю. и др. Синдром гиперандрогении в практике акушера-гинеколога, дерматолога, эндокринолога. Руководство для врачей. М: ГЭОТАР-Медиа, 2009.]

3. Vexiau $P$. et al. Acne in adult women: data from a national study on the relationship between type of acne and markers of clinical hyperandrogenism. Ann Dermatol Venerol 2002; 129

4. Araviyskaya Ye.R., Sokolovsky Ye.V. Systemic antibiotics therapy of acne: certain controversies. Vestn dermatol i venerol. 2013; 6: 177118. [Аравийская Е.Р., Соколовский Е.В. Системная антибиотикотерапия акне: некоторые дискуссионные вопросы. Вестн дерматол и венерол 2013; (6): 177-118.]

5. Thiboutot D., Gollnick H.P., Bettoli V., Dreno B. et al. New insights into the management of acne: An update from the Global Alliacne to improve outcomes in acne group. JAAD 2009; 60: 5 : 1 -50.

6. Samtsov A.V. Acne and acneformny dermatosis. M: YuTkom: 2009. [Самцов А.В. Акне и акнеформные дерматозы. М, 2009.]
7. Jeremy A.H., Holland D.B. Roberts S.G. et al. Inflammatory events are involved in acne lesions initiation. J Invest Dermatol. 2003 Jul; 121(1): 20-7.

8. Heymann WR. Toll-like receptors in acne vulgaris. J Am Acad Dermatol 2006; 55—691.

9. Isard O., Knol A.C., Aries M.F. et al. Proprionibacterium acnes activates the IGF-1/IGF-1R system in the epidermis and induces keratinocytes proliferation. J Invest Dermatol 2011; 131: 59-66.

10. Fitz-Gibbon S., Tomida S., Chiu B.H. et al Propionibacterium acnes Strain Populations in the Human Skin Microbiome Associated with Acne - Journal of Investigative Dermatology, 28.02.2013, doi: 10.1038/jid.2013.

11. Dummont-Wallon G., Dreno B. Specificity of acne in women older than 25 years. Presse Med 2008; 37: 585-591.

12. Williams C., Layton A.M. Persistent acne in women: implications for the patient and for therapy. Am J Clin Dermatol 2006; 7: 281—290.

13. Del Rosso J.Q., Bikowski J., Baum E. Prevalence of truncal acne vulgaris: a population study based on private practice experience. J Am Acad Dermatol; 2007; 56: AB3.

14. Colleir. Ch., Haper J., Cantell W. The prevalence of acne in adults 20 years and older. J Am Acad Dermatol. 2008; 58: 56—9.

15. Fitzpatricks T.B. Aeling J.L. Dermatology Secrets 1999. [Фицпатрик Т., Эллинг Д. Секреты дерматологии. СПб, 1999.]

16. Preneau, S., Dreno B. Female acne - a different subtype of teenager acne? JEADV 2012, 26 , 277-282

17. Textbook of dermatokosmetologii Araviyskaya Ye.R., Sokolovsky Ye.V. SPb.; Foliant, 2008. [Руководство по дерматокосметологии. Под ред. Е.Р. Аравийской и Е.В. Соколовского. СПб: «ФОЛИАНТ „, 2008.]
18. Rivera R., Guerra A. Management of acne in women over 25 years of age. Actas Dermosifiliogr 2009; 100: 33—37.

19. Melnik B.C., Schmitz G. Role of insulin, insulin-like growth factor-1, hyperglycaemic food and milk consumption in the pathogenesis of acne vulgaris. Exp Dermatol. 2009 0ct; 18(10): 833-41.

20. Bowe W. et all. Body dysmorphic disorder symptoms among patients with acne vulgaris. J Am Acad Dermatol. 2007; 57: 222—30.

21. Монахов С.А. Дифференцированная терапия акне с учетом тяжести кожного процесса и спектра психоэмоциональных расстройств: Афртореф. дис. канд. мед. наук. М, 2005.

22. Bodermer W. Psychosodermatology. The Medicine Journal 2001; 6, 297-302.

23. Tan J.K. et al. Divergence of demographic factors associated with clinical severity compared with quality of life impact in acne. J Cutan Med Surg 2008; 12(5): 235-42.

24. Kellett S.C., Gawkrodger D.J. The psychological and emotional impact of acne and the effect of treatment with isotretinoin. $\mathrm{Br} J$ Dermatol 1999; 140: 273-82.

25. GoryachkIna M.V. The role of psycho-emotional factors in the development of acne. Concilium Medicum Dermatologiya 2008; 2: 8-12. [Горячкина М.В. Роль психоэмоциональных фракторов в развитии акне. Concilium Medicum. Дерматология 2008; (2); 8-12.]

26. Acne. Clinical guidelines RODV M, 2010; 12 18. [Акне. Клинические рекомендации РОДВ. М: ДЭКС-ПРЕСС, 2010. 12—18.]

об авторах:

М.В. Горячкина — к.м.н., старший научный сотрудник лаборатории по изучению репаративных процессов в коже НОКЦ иммунозависимых дерматозов ГБОУ ВПО Первый МГМУ им. И.М. Сеченова Минздрава России, Москва

Т.А. Белоусова - к.м.н., доцент кафедры кожных и венерических болезней лечебного факультета ГБОУ ВПО Первый МГМУ им. И.М. Сеченова Минздрава России, Москва

\section{Конфликт интересов}

Авторы заявляют об отсутствии потенциального конфликта интересов, требующего раскрытия в данной статье 